\title{
Pre-fertilization zona pellucida hardening by different cross-linkers affects IVF in pigs and cattle and improves embryo production in pigs
}

\author{
Sebastian Canovas ${ }^{1}$, Raquel Romar ${ }^{1}$, Luis Alberto Grullon ${ }^{1}$, Manuel Aviles ${ }^{2}$ and Pilar Coy ${ }^{1}$ \\ ${ }^{1}$ Department of Physiology, Faculty of Veterinary Science and ${ }^{2}$ Department of Cell Biology and Histology, \\ School of Medicine, University of Murcia, Murcia 30071, Spain
}

Correspondence should be addressed to P Coy; Email: pcoy@um.es

\begin{abstract}
Zona pellucida (ZP) hardening (resistance to proteolysis) has been classically identified as a post-fertilization event that contributes to the block to polyspermy. $\mathrm{Di}$-(N-succinimidyl)-3,3'-dithiodipropionate (DSP), a permeable amine-reactive cross-linker, was recently shown to induce pre-fertilization ZP hardening and to improve porcine IVF productivity. The objectives of this study were to investigate i) how DSP affects pre-fertilization ZP hardening and IVF in cattle, ii) if a non-permeable amine-reactive cross-linker such as bis(sulfosuccinimidyl) suberate (BS3) affects ZP hardening and IVF in cattle and pigs, and iii) whether DSP or BS3, if improvement in IVF productivity was demonstrated in either species, affects in vitro embryo development. Bovine and porcine in vitro matured oocytes were incubated with the cross-linkers $(0.06,0.3$, and $0.6 \mathrm{mg} / \mathrm{ml})$ for $30 \mathrm{~min}$. Then they were subjected to ZP digestion or IVF. In cattle, both DSP and BS3 induced ZP hardening and decreased the penetration rate, although monospermy, penetration, or male pronuclear formation was not affected. In pigs, BS3 treatment induced ZP hardening, decreased penetration and male pronuclear formation, and increased monospermy. IVF productivity only improved when porcine oocytes were exposed to DSP. When porcine zygotes derived from this treatment were further cultured in vitro, the cleavage and blastocyst formation rates increased. These results support the idea that mechanisms involved in the prevention of polyspermic fertilization in cattle and pigs have different efficiencies, and ZP hardening induced by DSP cross-linker may be useful for improving porcine embryo production.
\end{abstract}

Reproduction (2009) 137 803-812

\section{Introduction}

Fertilization is one of the most fascinating processes in biology. It consists of the interaction between two (and only two) highly specialized haploid cells (gametes) to form a new diploid cell (zygote) that can develop into a completely new organism (van Beneden 1875, Miller et al. 2002). To achieve this $1: 1$ ratio in this interaction, oocytes from most mammals have evolved barriers against penetration by additional spermatozoa and micro-organisms, using both the oocyte's extracellular matrix zona pellucida (ZP) and the oocyte's secretory vesicles (cortical granules) that contain structural proteins and/or enzymes (Wong \& Wessel 2006).

Functions of the ZP have been widely studied (Topfer-Petersen \& Calvete 1995, Wang et al. 2003, Wassarman et al. 2005, Dean 2007, Hedrick 2007, Nixon et al. 2007). The regulation of the binding of spermatozoa, the establishment of species specifity, the protection of the zygote from lethal microorganisms or parasites, and the block to polyspermy at fertilization are among its classical roles. However, in domestic animals, this latter role of the ZP under in vitro conditions is not completely understood (Coy \& Romar 2002, Wang et al. 2003, Funahashi \& Romar 2004, Hao et al. 2006). In the mouse, the exocytosis of cortical granules, as a consequence of the fusion between a sperm and the oocyte, results in modification of the ZP (hardening), thereby avoiding binding and penetration of additional sperm (Ducibella et al. 1990, 1993, Vincent et al. 1990). In porcine and bovine oocytes, the events are very different. ZP resistance to pronase digestion has been used as a measurement of ZP hardening. ZP from bovine and porcine in vivo ovulated oocytes, without sperm contact, shows high resistance to protease digestion (from hours to days; Broermann et al. 1989, Kolbe \& Holtz 2005, Coy et al. 2008a). Additionally, it is well known that polyspermic fertilization occurs less frequently in vivo than in vitro (Hunter 1990). We have recently proposed that a pre-fertilization ZP hardening produced in vivo facilitates to control the degree of polyspermic penetration (Coy et al. 2008a). In vitro matured porcine and bovine oocytes, however, show a 
reduced ZP resistance to pronase (a few minutes; Iwamoto et al. 1999, Ko et al. 2008), even after the fertilization (Coy et al. 2002, 2005). While the physiological mechanisms involved are currently under investigation, an experimental approach inducing the ZP resistance by using chemical cross-linkers has been developed (Coy et al. 2008a).

After fertilization, ZP resistance to protease digestion has been partially attributed to cross-linking of the ZP to prevent unfolding of proteins (Green 1997). Previously, we have used di-( $N$-succinimidyl)-3, $3^{\prime}$-dithiodipropionate (DSP), a membrane permeable cross-linker that forms stable amide bonds among $\mathrm{NH}_{2}$ groups in protein, to induce ZP hardening in porcine and bovine matured oocytes (Coy et al. 2008a). The results showed that the pre-fertilization ZP hardening induced by DSP in pig had a dose-dependent effect on penetration and monospermic penetration, which improved the final IVF productivity when using intermediate concentrations of the crosslinker. In the present study, we have tried to extend the available knowledge of the use of DSP to bovine oocytes and to investigate the effect of another cross-linker on pre-fertilization ZP hardening and IVF yield. Furthermore, we investigated whether the cross-linker would have a beneficial effect on embryo development after IVF. The cross-linker bis(sulfosuccinimidyl) suberate (BS3) was selected because BS3 also acts on primary amines and it forms stable amide bonds among proteins like DSP; however, it is non-permeable. Therefore, this property of BS3 enabled us to study cell-surface protein cross-linking and avoid possible collateral effects of the cross-linker treatment on biochemical machinery of the oocyte that may occur with DSP.

The specific objectives of the present work were: i) to study how DSP used at different concentrations affects pre-fertilization ZP hardening, sperm binding to ZP and IVF in cattle, ii) to evaluate the effect of different concentrations of BS3 in ZP hardening and IVF both in cattle and pigs, and iii) to examine whether DSP or BS3, if improvement in IVF productivity was demonstrated in either species, affects in vitro embryo development. In accordance with our previous (Coy et al. 2008a) and present studies, there was only an improvement in porcine IVF productivity after DSP exposure of the oocytes. Neither DSP nor BS3 significantly improves bovine IVF productivity. Therefore, only the effects of DSP on porcine embryo production were assessed.

\section{Results}

\section{Experiment 1: effect of different DSP concentrations on cow $Z P$ resistance to pronase, sperm- $Z P$ binding, and IVF output}

The results showed that DSP increased the ZP resistance to pronase in bovine oocytes in a dose-dependent manner (Table 1). The ZP digestion time significantly increased from $95.08 \pm 4.36$ (control group) to $2759.86 \pm 123.21 \mathrm{~s}$ (DSP $0.6 \mathrm{mg} / \mathrm{ml} ; \quad P<0.01$ ), and thus an increase of approximately 39 fold. The intermediate DSP concentrations also showed a significant increase in ZP hardening compared with the control group $(P<0.01)$.

When the DSP-treated bovine oocytes were inseminated, a significant decrease in penetration rate was observed for all groups compared with untreated oocytes (Table 1); however, a dose effect by the cross-linker was not observed on rate of penetration. Moreover, the treatment of bovine oocytes with DSP before IVF did not affect the rate of monospermic penetration, mean number of spermatozoa per penetrated oocyte, or male pronuclear formation (Table 1).

The observed reduction in penetration rate in the presence of the cross-linkers was investigated by examining the sperm-ZP binding. This was carried out in order to evaluate whether the reduction was caused by a reduction in the number of sperm bound to the ZP or due to the prevention of sperm penetration by the hardening of the ZP. The results showed there were no significant differences between the control group and the DSP groups in the number of sperm bound per oocyte after insemination (Fig. 1A, $P=0.785$ ), and therefore the decrease in the penetration rate was not likely to be due to a depreciation of sperm-ZP binding. When the data were further analyzed to consider the penetration status of the oocyte, no significant difference was observed in penetrated or non-penetrated oocytes in each concentration (Fig. 1B, $P>0.05$ ).

Table 1 Effect of treatment of cow oocytes with di-(N-succinimidyl)-3,3'-dithiodipropionate (DSP) cross-linker at different concentrations on zona pellucida (ZP) resistance to pronase and IVF results.

\begin{tabular}{lccc}
\hline Treatment & ZP dt $(N)$ & \%PEN $(N)$ & \%MON \\
\hline Control & $95.08 \pm 4.36^{\mathrm{a}}(99)$ & $76.23 \pm 3.87^{\mathrm{a}}(122)$ & $82.80 \pm 3.93$ \\
DSP $0.06 \mathrm{mg} / \mathrm{ml}$ & $971.80 \pm 111.56^{\mathrm{b}}(115)$ & $23.48 \pm 3.70^{\mathrm{b}}(132)$ & $83.87 \pm 6.71$ \\
DSP $0.3 \mathrm{mg} / \mathrm{ml}$ & $1508.05 \pm 125.08^{\mathrm{c}}(119)$ & $29.46 \pm 4.02^{\mathrm{b}}(129)$ & $97.00 \pm 1.80$ \\
DSP $0.6 \mathrm{mg} / \mathrm{ml}$ & $2759.86 \pm 123.21^{\mathrm{d}}(102)$ & $20.49 \pm 3.66^{\mathrm{b}}(122)$ & $1.16 \pm 0.05$ \\
\hline
\end{tabular}

$\mathrm{a}, \mathrm{b}, \mathrm{c}, \mathrm{d}$ Different letters in the same column indicate significant differences $(P<0.01)$. ZP dt, zona pellucida digestion time (seconds);

$\% \mathrm{PEN}$, penetration percentage from $\mathrm{N} ; \mathrm{N}$, number of oocytes; \%MON, monospermy percentage calculated from penetrated oocytes; SPZ/O, mean number of sperm per penetrated oocyte; \%MPN, percentage of male pronuclear formation from penetrated oocytes. 

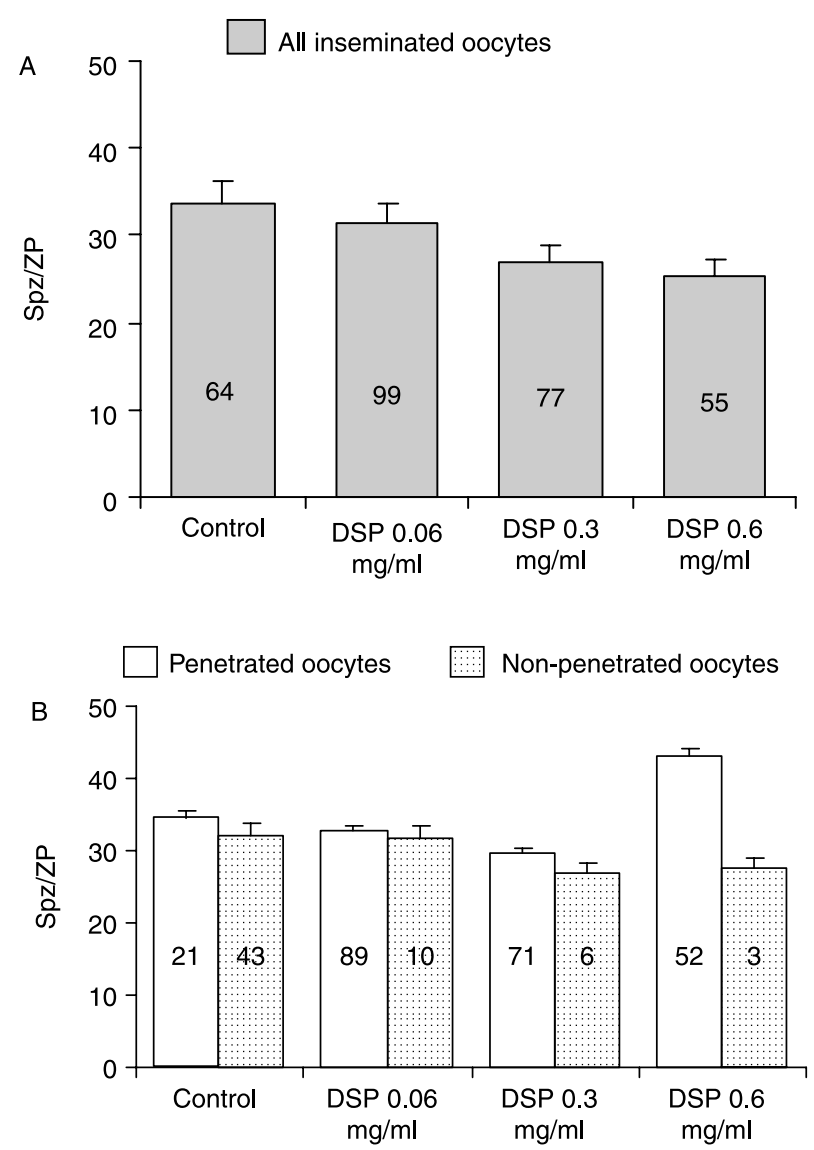

Figure 1 Number of sperm bound to ZP (Spz/ZP) in cow oocytes treated with DSP at different concentrations before insemination. (A) Data for all inseminated oocytes independently of oocyte penetration status. (B) Data presented separately for penetrated and non-penetrated oocytes. The number of oocytes is shown in each bar.

\section{Experiment 2: effect of different BS3 concentrations on bovine $Z P$ resistance to pronase, sperm-ZP binding, and IVF output}

The ZP pronase resistance to proteolysis increased in a dose-dependent manner from $1457.41 \pm 102.80 \mathrm{~s}$ $(0.06 \mathrm{mg} / \mathrm{ml})$ to $3480.94 \pm 79.28 \mathrm{~s}(0.6 \mathrm{mg} / \mathrm{ml})$, while the ZP in control oocytes was digested in only 89.63 \pm 4.84 s (Table 2 ) when oocytes were exposed to BS3. When oocytes were inseminated, those treated with BS3 cross-linker showed a decrease in the percentage of penetration in bovine oocytes (Table $2, P<0.01$ ) in a dose-dependent manner, reaching the lowest penetration rate at the highest BS3 concentration. However, BS3 treatment did not affect the percentage of monospermy (over $80 \%$ in all groups), nor the mean number of spermatozoa per oocyte or male pronucleus formation (Table 2), in concordance with the results obtained in experiment 1 with DSP (Table 1).

The number of sperm bound per oocyte significantly decreased only with the highest BS3 concentration compared with control group $(30.63 \pm 2.52$ vs 21.78 \pm 1.56 ; $P=0.013$, Fig. 2A). The intermediate BS3 concentrations did not have significant effects. When penetrated and non-penetrated oocytes were assessed separately for the number of sperm bound for each crosslinker concentration, a significant effect of oocyte penetration was observed (Fig. 2B, $P<0.05$,). The number of sperm bound to non-penetrated oocytes, treated with BS3, was lower than those bound to penetrated oocytes.

\section{Experiment 3: effect of different BS3 concentrations on pig ZP resistance to pronase and IVF output}

In pigs, BS3 produced a significant increase in the ZP pronase resistance to proteolysis in a dose-dependent manner (Table 3), similar to the results observed for this cross-linker in cow oocytes (Table 2).

The BS3 treatment results showed that the penetration rate decreased significantly from $80 \%$ (control oocytes) to $\sim 20 \%$ (BS3-treated oocytes). Similar results were obtained when male pronuclear formation was assessed (Table 3). However, BS3 treatment significantly increased monospermic penetration rate in porcine oocytes from $10.1 \%$ (control oocytes) to more than $85 \%$ (BS3-treated oocytes). The mean number of spermatozoa per penetrated oocytes was significantly reduced in all treated groups to $\sim 1: 1$ sperm to oocyte ratio, in contrast to the control group where it was around 5:1. No effect of BS3 concentration was observed on IVF results, in contrast to the dose effect observed on ZP digestion time.

\section{Experiment 4: effect of DSP on porcine embryo production using optimized conditions}

Finally, the effect of DSP at $0.06 \mathrm{mg} / \mathrm{ml}$ on porcine embryo development was tested using an optimized IVF system to maximize monospermic penetration rate

Table 2 Effect of treatment of cow oocytes with bis(sulfosuccinimidyl) suberate (BS3) cross-linker at different concentrations on zona pellucida (ZP) resistance to pronase and IVF results.

\begin{tabular}{|c|c|c|c|c|c|}
\hline Treatment & ZP dt $(N)$ & $\%$ PEN $(N)$ & $\% M O N$ & SPZ/O & $\%$ MPN \\
\hline Control & $89.63 \pm 4.84^{\mathrm{a}}(84)$ & $60.95 \pm 4.78^{\mathrm{a}}(105)$ & $90.63 \pm 3.67$ & $1.10 \pm 0.04$ & $95.00 \pm 2.70$ \\
\hline BS3 $0.06 \mathrm{mg} / \mathrm{ml}$ & $1457.41 \pm 102.28^{\mathrm{b}}(120)$ & $41.51 \pm 4.80^{\mathrm{b}}(106)$ & $90.91 \pm 4.38$ & $1.09 \pm 0.05$ & $95.00 \pm 3.20$ \\
\hline BS3 $0.3 \mathrm{mg} / \mathrm{ml}$ & $2877.78+82.48^{\mathrm{C}}(110)$ & $27.78+4.00^{\mathrm{b}}(126)$ & $80.00+6.86$ & $1.14+0.09$ & $89.00+5.50$ \\
\hline BS3 $0.6 \mathrm{mg} / \mathrm{ml}$ & $3480.94 \pm 79.28^{d}(117)$ & $9.73 \pm 2.80^{\mathrm{C}}(113)$ & $90.91 \pm 9.09$ & $1.09 \pm 0.09$ & 100 \\
\hline
\end{tabular}

${ }_{a, b, c, d}$ Different letters in the same column indicate significant differences $(P<0.01)$. ZP dt, zona pellucida digestion time $(s)$; \%PEN, penetration percentage from $N ; N$, number of oocytes; \%MON, monospermy percentage calculated from penetrated oocytes; SPZ/O, mean number of sperm per penetrated oocyte; \%MPN, percentage of male pronuclear formation from penetrated oocytes. 

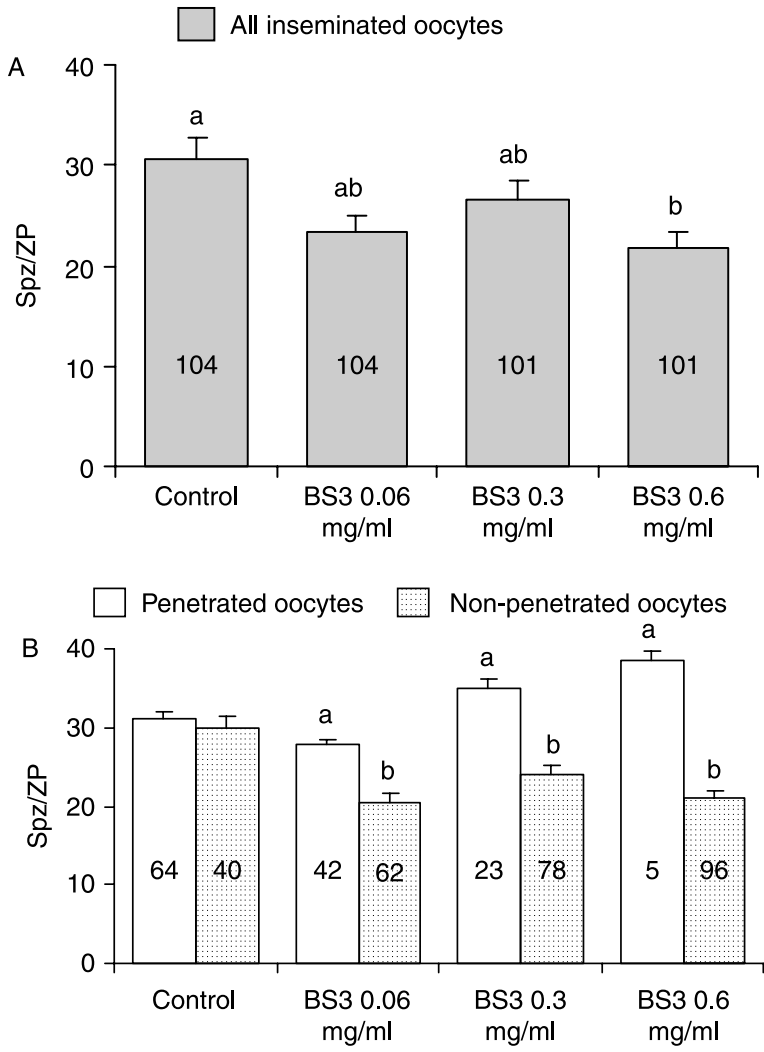

Figure 2 Number of sperm bound to ZP (Spz/ZP) in cow oocytes treated with BS3 at different concentrations before insemination. (A) Data for all inseminated oocytes independently of their penetration status. Different letters between groups indicate significant differences $(P<0.05)$. (B) Data presented separately for penetrated and nonpenetrated oocytes. Different letters in the same cross-linker concentration indicate significant differences $(P<0.05)$. The number of oocytes is shown in each bar.

(with short coincubation time, see Materials and Methods section). Inseminated oocytes incubated with the cross-linker were fixed at $22 \mathrm{~h}$ post-insemination to evaluate the IVF parameters or allowed to develop. The results showed that the treatment increased significantly the monospermy and IVF efficiency (Table 4). Moreover, the cleavage rate increased compared with the control group (Fig. 3, $P=0.032 ;$ ). No significant differences were observed in the blastocyst formation rate between control $(11.50 \pm 4.10)$ and DSP $(20.60 \pm 5.10)$ groups
$(P=0.168)$. However, when the rate of blastocyst formation was calculated from the total number of inseminated oocytes, the DSP-derived zygotes had a significantly higher rate of blastocyst formation $(P=0.05)$, although rates of blastocyst formation were low in both control- and DSP-treated groups, $5.93 \pm 2.18$ and $13.68 \pm 3.54$ respectively.

\section{Discussion}

Selective pressure to achieve monospermic penetration has resulted in elaborate and diverse structures of the oocyte and spermatozoa. The most established mechanism involves physically inhibiting the binding/ fusion of additional sperm to the ZP, plasma membrane, or both structures (Austin \& Braden 1953, Wong \& Wessel 2006). ZP hardening has been considered to be a postfertilization event necessary to avoid the penetration of additional sperm (Ducibella et al. 1990, 1993, Vincent et al. 1990), and includes a resistance to sperm penetration and a resistance of the ZP to proteolytic digestion. We have observed that this post-fertilization hardening, at least in the ZP resistance to proteolysis, does not occur in bovine and porcine in vitro matured oocytes inseminated in vitro (Coy et al. 2002, 2005). However, a pre-fertilization ZP resistance occurs in in vivo ovulated bovine and porcine oocytes (Broermann et al. 1989, Kolbe \& Holtz 2005, Coy et al. 2008a). Given this distinctive of in vivo pre-fertilization ZP resistance to proteolysis, in a recent study, we have been able to induce such a hardening chemically under in vitro conditions by incubating porcine and bovine oocytes with the DSP cross-linker before insemination (Coy et al. 2008a). We were able to confirm these observations with the results in the present study using BS3, a non-permeable cross-linker with a similar mechanism to DSP.

Results from the present study show that exposure to DSP increases the ZP resistance to proteolysis of bovine oocytes in a dose-dependent manner, as previously reported in pigs (Coy et al. 2008a). Additionally, BS3 treatment also increased the $\mathrm{ZP}$ resistance both in bovine and porcine oocytes in similar proportions. Both species possess an equivalent number of $\mathrm{NH}_{2}$ groups, upon which the cross-linkers act and therefore a similarity in results were expected between bovine and porcine

Table 3 Effect of treatment of pig oocytes with bis(sulfosuccinimidyl) suberate (BS3) cross-linker at different concentrations on zona pellucida (ZP) resistance to pronase and IVF results.

\begin{tabular}{lccccc}
\hline Treatment & ZP dt $(N)$ & \%PEN $(N)$ & \%MON & SPZ/O & \%MPN \\
\hline Control & $69.09 \pm 3.46^{\mathrm{a}}(108)$ & $83.10 \pm 4.10^{\mathrm{a}}(83)$ & $10.10 \pm 3.70^{\mathrm{a}}$ & $5.00 \pm 0.30^{\mathrm{a}}$ & $99.00 \pm 1.40^{\mathrm{a}}$ \\
BS3 $0.06 \mathrm{mg} / \mathrm{ml}$ & $426.26 \pm 61.17^{\mathrm{b}}(76)$ & $22.20 \pm 7.00^{\mathrm{b}}(86)$ & $100^{\mathrm{b}}$ & $1.00 \pm 00^{\mathrm{b}}$ & $25.00 \pm 16.40^{\mathrm{b}}$ \\
BS3 $0.3 \mathrm{mg} / \mathrm{ml}$ & $2358.64 \pm 107.06^{\mathrm{c}}(64)$ & $18.10 \pm 4.00^{\mathrm{b}}(94)$ & $88.20 \pm 8.10^{\mathrm{b}}$ & $1.1 \pm 0.10^{\mathrm{b}}$ & $35.30 \pm 11.90^{\mathrm{b}}$ \\
BS3 $0.6 \mathrm{mg} / \mathrm{ml}$ & $2979.15 \pm 83.03^{\mathrm{d}}(76)$ & $21.50 \pm 4.30^{\mathrm{b}}(93)$ & $95.00 \pm 5.00^{\mathrm{b}}$ & $1.10 \pm 0.10^{\mathrm{b}}$ & $50.00 \pm 13.60^{\mathrm{b}}$ \\
\hline
\end{tabular}

$\overline{a, b, c, d}$ Different letters in the same column indicate significant differences $(P<0.01)$. ZP dt, zona pellucida digestion time $(\mathrm{s}), \%$ PEN, penetration percentage from $N ; N$, number of oocytes; \%MON, monospermy percentage calculated from penetrated oocytes; SPZ/O, mean number of sperm per penetrated oocyte; \%MPN, percentage of male pronuclear formation from penetrated oocytes. 
Table 4 Effect of treatment of pig oocytes with di-(N-succinimidyl)-3,3'-dithiodipropionate (DSP) cross-linker on IVF parameters, using a short coincubation time.

\begin{tabular}{lcccrr}
\hline Treatment & \%PEN $(N)$ & \%MON & SPZ/O & \%MPN & \% OUTPUT \\
\hline Control & $88.17 \pm 3.37(93)$ & $31.7 \pm 5.17^{\mathrm{a}}$ & $2.53 \pm 0.16$ & $97.56 \pm 1.71$ & $30.11 \pm 4.78^{\mathrm{a}}$ \\
DSP 0.06 mg/ml & $87.36 \pm 3.58(87)$ & $47.37 \pm 5.77^{\mathrm{b}}$ & $2.10 \pm 0.18$ & $98.68 \pm 1.32$ & $43.68 \pm 5.35^{\mathrm{b}}$ \\
\hline
\end{tabular}

\footnotetext{
${ }^{\mathrm{a}, \mathrm{b}}$ Different letters in the same column indicate significant differences $(P<0.05) . N$, number of oocytes; PEN, penetration percentage from $N$; SPZ/O, mean number of sperm per penetrated oocyte; \%MPN, percentage of male pronuclear formation from penetrated oocytes; \%MON, monospermy percentage calculated from penetrated oocytes; OUTPUT, percentage of monospermic oocytes from the total of inseminated oocytes.
}

oocytes. A comparative study was carried out in order to investigate whether there are differences in effectiveness of the mechanisms that inhibit polyspermic penetration, because it is well known that the incidence of polyspermic fertilization is much lower in bovine IVF (Iwata et al. 2008, Wang et al. 2007) than in porcine IVF (Hancock 1959, Funahashi \& Romar 2004, Hao et al. 2006). Furthermore, a standard protocol incorporating cross-linkers in IVF, particularly due to the ability of cross-linkers to induce ZP hardening, may facilitate other problems associated with IVF including resistance to infection by viruses (Bielanski et al. 2003), such as the transmission of bovine viral diarrhoea virus in abattoirderived in vitro produced embryos (Perry 2007).

In this study, no significant difference was observed in polyspermic penetration rates of bovine oocytes exposured to different doses of DSP unlike previous observation in porcine oocytes (Coy et al. 2008a), even though the $\mathrm{ZP}$ resistance to pronase digestion was increased. When oocyte ZP hardening was induced with BS3, differences in effect on IVF efficiency were observed between pigs and cattle. Previous reports have shown species-specific differences in the prevention of polyspermic penetration and the relevance of a resistant ZP to control sperm penetration. For example, the oviduct-specific glycoprotein (OGP), which is involved in the control of polyspermy (Coy et al. 2008b), improves bovine and porcine IVF outputs (Martus et al. 1998, Kouba et al. 2000), although studies using OGP knockout mice showed no significant differences in IVF and

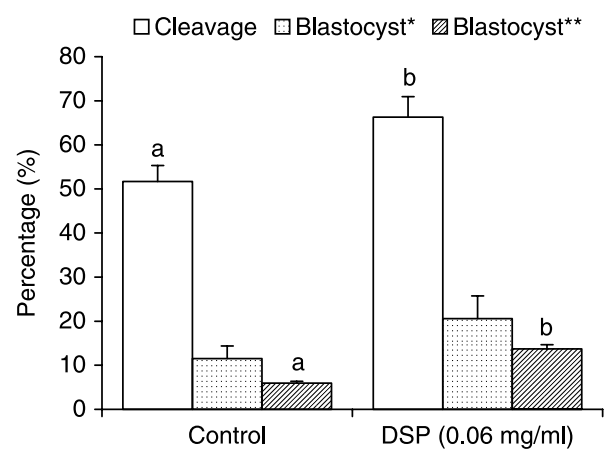

Figure 3 Porcine embryo production using oocytes treated with DSP $(0.06 \mathrm{mg} / \mathrm{ml})$. a,b: different letters for the same parameter indicate significant differences between groups $(P<0.05)$. Cleavage: two- to four-cell stage embryos. Blastocyst*, calculated from cleaved embryos. Blastocyst*: calculated from inseminated oocytes. in vivo fertilization (Araki et al. 2003). In the mouse, the degree of spontaneous zona hardening is directly correlated with the failure of fertilization (Gianfortoni \& Gulyas 1985, Ducibella et al. 1990) showing the role of ZP hardening in the sperm penetration. However, insemination of mouse zona-free eggs resulted in more than $50 \%$ of monospermic eggs (Florman \& Ducibella 2006), showing that the plasma membrane has one additional role in the inhibition of polyspermic penetration. In others species such as rabbit, pika, mole, or bat, the primary mechanism in preventing polyspermic fertilization is by blocking the plasma membrane (Yanagimachi 1994, Florman \& Ducibella 2006). In both pig and cow species, in vivo ovulated oocytes show a pre-fertilization ZP resistance to proteolytic digestion (Broermann et al. 1989, Kolbe \& Holtz 2005, Coy et al. 2008a). Fulka et al. (1982) showed the fertilization of bovine ZP-free oocytes with monospermic penetration was close to $50 \%$ (Fulka et al. 1982), although our own observations show that in porcine ZP-free oocytes the polyspermic penetration is close to $100 \%$ (S Canovas, unpublished observations). In the present study, bovine ZP-enclosed oocytes showed a negative correlation between an increase in ZP hardening and a decrease in sperm penetration. We propose that the control of polyspermy under in vitro conditions in cattle may emulate the murine model more than reflect a porcine model, thus involving both plasma membrane and ZP. This hypothesis may explain the differences in the incidence of polyspermic penetration between pigs and cattle. If the ZP is the major barrier responsible of the block to polyspermy in pigs, under in vitro conditions, the pre-fertilization ZP resistance to proteolysis has a greater importance to control polyspermy in pigs than in cows. Additionally, these results support the idea that the crosslinker treatments are useful to investigate the role of the ZP hardening on fertilization.

The masking of the sperm-binding ligands has been proposed as another consequence of the ZP modification (hardening) after fertilization (Green 1997). In fact, in the supramolecular structure model proposed in the mouse, the zona glycoproteins form a three-dimensional matrix to which sperm can bind and, as a consequence of fertilization, a cortical granule protease cleaves ZP2 rendering ZP unable to support sperm binding by altering such supramolecular structure (Rankin et al. 2003, Dean 2007). Theoretically, the pre-fertilization ZP 
hardening as a consequence of the cross-linker treatments could lead to a similar effect by decreasing the ability of the ZP to bind spermatozoa. To rule it out, using the sperm-ZP binding assay, we observed that the reduction in the penetration rate in cattle using DSP was mainly due to an increase in the difficulty of the sperm to penetrate the ZP probably associated with ZP resistance to enzymes (Aitken \& Vernet 1998) and not to 'chemical' modifications in the ZP sites to bind spermatozoa. However, in cow oocytes treated with the highest concentration of BS3, the ability of ZP to bind spermatozoa was reduced compared with control. This could be due to possible modifications not only in proteins but also in carbohydrate moieties at the ZP level (Yazawa et al. 1995) responsible for the sperm binding. The results showing a significant effect of the highest BS3 concentration on penetration rate in cow, differently from DSP effect, support also this hypothesis.

The present study also showed a negative effect on male pronuclear formation by BS3 in pigs. The same detrimental effect on male pronuclear formation in pig oocytes has been observed when oocytes are incubated with osteopontin, a protein that increases ZP digestion time and decreases penetration, although authors were unable to explain this observation (Hao et al. 2006, 2008). In this study, we propose that the non-permeable cross-linker BS3 may have had an effect on oolemma proteins that act as ligands for spermatozoa, and are responsible for the induction of external-internal signalling for oocyte activation, gamete fusion, and pronuclear formation (Boni et al. 2007, Pate et al. 2008). The observed differences between the results for the porcine and bovine oocytes also support the idea that there are specific species differences in the effectiveness of the mechanisms regulating polyspermy.

Porcine and bovine in vitro embryo production is still an inefficient process. Although the in vitro maturation and fertilization proceed with standard regularity, the proportion of embryos that reach the blastocyst stage is rarely over $40 \%$ in cattle (Lonergan \& Fair 2008), while in pigs, proportions rarely reach $20 \%$ (Nagai et al. 2006). The main causes for these inefficiencies are very distinct differences between cattle and pig, where polyspermic fertilization is a major problem in pigs. In this study, we suggest the use of cross-linkers before IVF to reduce the incidence of polyspermy, and thus improve embryo production as a new approach to increase the success of the technique. The results in porcine embryos showed that DSP-derived zygotes are able to develop to the blastocyst stage at higher rate than oocytes not exposed to the cross-linker, showing a positive effect of the cross-linker treatment. Even though DSP is a membranepermeable cross-linker, these results show that it can be used without altering early embryo development.

In this work, DSP showed an effect on ZP digestion time, sperm penetration, and monospermy like in our previous paper, although the absolute values are different, which can be explained by the variability that happens in biological assays.

In summary, this study shows that both DSP and BS3 cross-linkers induce pre-fertilization ZP hardening (resistance to proteolysis and to sperm penetration) in cattle and pig. In cattle, both cross-linkers were able to decrease penetration rate without affecting monospermic fertilization or male pronuclear formation. In pigs, only DSP treatment improved embryo development. This new approach may be used to study the sperm-oocyte interactions and the prevention of polyspermic fertilization. This approach may be applied to improve in vitro pig embryo production.

\section{Materials and Methods}

\section{Culture media}

Unless otherwise indicated, all chemicals and reagents were purchased from Sigma-Aldrich Química S.A.

The medium used for pig oocyte maturation was NCSU-37 (Petters \& Wells 1993) supplemented with $0.57 \mathrm{mM}$ cysteine, $1 \mathrm{mM}$ dibutyryl cAMP, $5 \mu \mathrm{g} / \mathrm{ml}$ insulin, $50 \mu \mathrm{M} \beta$-mercaptoethanol, $10 \mathrm{IU} / \mathrm{ml}$ eCG (Folligon, Intervet International B.V., Boxmeer, Holland), $10 \mathrm{IU} / \mathrm{ml}$ hCG (Veterin corion, Divasa Farmavic, Barcelona, Spain), and $10 \%$ porcine follicular fluid $(\mathrm{v} / \mathrm{v})$. The basic medium used for pig IVF was essentially the same as that used by Rath et al. (1999). This medium, designated as TALPp medium, consists of $114.06 \mathrm{mM} \mathrm{NaCl}, 3.2 \mathrm{mM} \mathrm{KCl}$, $8 \mathrm{mM}$ Ca-lactate $5 \mathrm{H}_{2} \mathrm{O}, 0.5 \mathrm{mM} \mathrm{MgCl} 26 \mathrm{H}_{2} \mathrm{O}, 0.35 \mathrm{mM}$ $\mathrm{NaH}_{2} \mathrm{PO}_{4}, 25.07 \mathrm{mM} \mathrm{NaHCO}, 10 \mathrm{mM} \mathrm{Na}$ lactate, $1.1 \mathrm{mM}$ Na-pyruvate, $5 \mathrm{mM}$ glucose, $2 \mathrm{mM}$ caffeine, $3 \mathrm{mg} / \mathrm{ml}$ BSAFAF (A-6003), $1 \mathrm{mg} / \mathrm{ml}$ polyvinyl alcohol (PVA), and $0.17 \mathrm{mM}$ kanamycin sulfate. The embryo culture medium was NCSU-23, containing $0.4 \% \quad(\mathrm{w} / \mathrm{v}) \quad \mathrm{BSA}, 75 \mu \mathrm{g} / \mathrm{ml}$ potassium penicillin $\mathrm{G}$, and $50 \mu \mathrm{g} / \mathrm{ml}$ streptomycin sulfate (Machaty et al. 1998).

The in vitro maturation medium for cow oocytes was TCM199 with Earle's salts, 10\% (v/v) fetal bovine serum (FBS), $2 \mathrm{mM}$ L-glutamine, $0.2 \mathrm{mM}$ sodium pyruvate, $50 \mathrm{mg} / \mathrm{ml}$ gentamicin, $10 \mathrm{IUml}$ eCG (Folligon, Intervet International B.V.), and $10 \mathrm{IU} / \mathrm{ml}$ hCG (Veterin corion, Divasa Farmavic). The IVF medium was TALP consisting of $114 \mathrm{mM} \mathrm{NaCl}, 3,2 \mathrm{mM} \mathrm{KCl}$, $0.5 \mathrm{mM} \mathrm{MgCl}{ }_{2} 6 \mathrm{H}_{2} \mathrm{O}, 10 \mathrm{mM}$ Na lactate, $0.3 \mathrm{mM} \mathrm{NaH}_{2} \mathrm{PO}_{4}$ $\mathrm{H}_{2} \mathrm{O}, 25 \mathrm{mM} \mathrm{NaHCO}, 0.2 \mathrm{mM}$ Na-pyruvate, $2 \mathrm{mM} \mathrm{CaCl}$ $2 \mathrm{H}_{2} \mathrm{O}, 6 \mathrm{mg} / \mathrm{ml}$ BSA-FAF (A-6003), $1.75 \mathrm{IU} / \mathrm{ml}$ heparin, $50 \mathrm{IU} / \mathrm{ml}$ penicillin, and $50 \mu \mathrm{g} / \mathrm{ml}$ streptomycin (Parrish et al. 1986). This medium is designated as TALPb.

\section{Oocyte collection and in vitro maturation}

\section{Pig}

Within 30 min of slaughter, ovaries from gilts were transported to the laboratory in saline containing $100 \mu \mathrm{g} / \mathrm{ml}$ kanamycin sulfate at $38{ }^{\circ} \mathrm{C}$, washed once in $0.04 \%$ cetrimide solution, and twice in saline. Oocyte-cumulus cell complexes (COCs) were collected from antral follicles (3-6 mm diameter), washed twice with DPBS supplemented with $1 \mathrm{mg} / \mathrm{ml}$ PVA and $0.005 \mathrm{mg} / \mathrm{ml}$ 
red phenol, and twice more in maturation medium previously equilibrated for a minimum of $3 \mathrm{~h}$ at $38.5^{\circ} \mathrm{C}$ under $5 \% \mathrm{CO}_{2}$ in air. Only COCs with a complete and dense cumulus oophorus were used for the experiments. Groups of 50 COCs were cultured in $500 \mu \mathrm{l}$ maturation medium for $22 \mathrm{~h}$ at $38.5{ }^{\circ} \mathrm{C}$ under $5 \% \mathrm{CO}_{2}$ in air. After culture, oocytes were washed twice in fresh maturation medium without dibutyryl cAMP, eCG, and hCG, and cultured for an additional 20-22 h (Funahashi et al. 1997).

\section{Cow}

Cow COCs were collected by aspiration from non-atretic follicles (2-6 mm diameter) of ovaries from the slaughterhouse. All the ovaries came from animals between 14 and 20 months old, and only those at the follicular phase of the oestrous cycle (Orsi et al. 2005) were used. COCs were then washed twice in TCM-199 with Hank's salts, 10.0 mM HEPES, 2\% FBS, $2.0 \mathrm{mM}$ glutamine, $50 \mathrm{IU} / \mathrm{ml}$ penicillin, and $50 \mu \mathrm{g} / \mathrm{ml}$ streptomycin, and once in maturation medium previously equilibrated for $4 \mathrm{~h}$ at $38.5{ }^{\circ} \mathrm{C}$ under $5 \% \mathrm{CO}_{2}$ in air. Groups of $50 \mathrm{COCs}$ were cultured in $500 \mu \mathrm{l}$ maturation medium for $22 \mathrm{~h}$ at $38.5^{\circ} \mathrm{C}$ under $5 \% \mathrm{CO}_{2}$ in air.

\section{Incubation of bovine and porcine IVM oocytes with DSP and BS3}

Two cross-linkers that form stable amine bonds among proteins were used. DSP (DSP or Lomant's reagent) was diluted in dimethylsulfoxide at a concentration of $25 \mathrm{mg} / \mathrm{ml}$ and stored frozen at $-80^{\circ} \mathrm{C}$ until used. BS3 (Pierce, Rockford, IL, USA) was prepared immediately before use in a non-amine-containing aqueous buffer (DPBS) at $\mathrm{pH} \mathrm{7,} \mathrm{at} 30 \mathrm{mg} / \mathrm{ml}$, following the manufacturer's instructions.

After the maturation period (42-44 $\mathrm{h}$ in porcine and $22 \mathrm{~h}$ in bovine), cumulus cells were removed by pipetting, and denuded oocytes were incubated for $30 \mathrm{~min}$ with the different cross-linkers at final concentration of $0.06,0.3$, or $0.60 \mathrm{mg} / \mathrm{ml}$, as we have previously described (Coy et al. 2008a). Cow oocytes were incubated with any of the two cross-linkers (DSP and BS3) and pig oocytes only with BS3. A group of oocytes incubated in IVF medium (TALPp in pig and TALPb in cow) for 30 min without any cross-linker was used as a control group in all the experiments. After the incubation period, the oocytes were gently washed thrice in fresh IVF medium: one aliquot was used to asses the ZP digestion time and the remaining oocytes transferred to IVF medium for insemination.

\section{Assessment of ZP solubility}

Matured oocytes, after incubation with or without cross-linker for $30 \mathrm{~min}$, were gently washed in DPBS and transferred in groups of $10-15$ oocytes, into $50 \mu \mathrm{l}$ of $0.5 \%$ (w/v) pronase solution in DPBS (Coy et al. 2002). The ZP was observed continuously for dissolution under an inverted microscope equipped with a warm plate at $37^{\circ} \mathrm{C}$. The dissolution time for the zona of each oocyte was registered as the time interval between placement of the samples in pronase solution and when the zona was no longer visible at a magnification of $200 \times$. This time was named as ZP digestion time (ZP dt).

\section{IVF}

Pig

Porcine in vitro matured oocytes, after incubation with or without cross-linker for $30 \mathrm{~min}$, were washed thrice with TALPp medium and groups of 30-35 oocytes were transferred into each well of a four-well multidish containing $250 \mu \mathrm{l}$ of TALPp medium pre-equilibrated at $38.5^{\circ} \mathrm{C}$ under $5 \% \mathrm{CO}_{2}$. Fresh semen diluted 1:1 in Beltsville thawing solution (Pursel \& Johnson 1975) from a mature, fertility tested boar was used. Spermatozoa were obtained by centrifugation of $0.5 \mathrm{ml}$ of semen on a 45/90 discontinuous Percoll (Pharmacia) gradient, and the resultant sperm pellets were diluted in TALPp medium and centrifuged again for $10 \mathrm{~min}$ at $100 \mathrm{~g}$. Finally, the pellet was diluted in TALPp, and $250 \mu \mathrm{l}$ of the suspension were added to wells with oocytes to a final concentration of $1 \times 10^{5}$ cells $/ \mathrm{ml}$. Gametes were coincubated for $4 \mathrm{~h}$ in experiment 3 and for $15 \mathrm{~min}$ in experiment 4 , to maximize the possibilities of monospermic penetrations. After coincubation time, putative zygotes were washed twice with fresh TALPp by gentle aspiration through a glass pipette and allowed to continue in culture at $38.5^{\circ} \mathrm{C}$ under $5 \% \mathrm{CO}_{2}$ until fixation (at $22 \mathrm{~h}$ post-insemination - hpi - in experiment 3 and at $168 \mathrm{hpi}$ in experiment 4, where blastocyst formation was evaluated). The rationale of this methodology is based on using an optimized IVF system for porcine embryo production (Funahashi \& Romar 2004).

\section{Cow}

The mature oocytes, after incubation with or without crosslinker for $30 \mathrm{~min}$, were washed three times in fresh IVF medium, and groups of 30-40 oocytes were transferred to wells containing $500 \mu \mathrm{l}$ of TALPb medium. A volume of $25 \mu \mathrm{l}$ (penicillamine-hypotaurine-epinephrine; Parrish et al. 1986) was added to each well $\sim 30 \mathrm{~min}$ before insemination. Spermatozoa were obtained by centrifugation of two $0.5 \mathrm{ml}$ straws of frozen-thawed semen on a 45/90 discontinuous Percoll gradient for $10 \mathrm{~min}$ at $900 \mathrm{~g}$. The pellet was resuspended in $10 \mathrm{ml}$ sperm-TALP medium (Parrish et al. 1986) and washed again for $8 \mathrm{~min}$ at $300 \mathrm{~g}$. The final pellet was resuspended in $500 \mu \mathrm{l}$ TALPb, sperm concentration adjusted, and cells added at a final concentration of $1.5 \times 10^{6}$ spermatozoa/ml to the wells containing the oocytes. At 18-20 hpi, putative zygotes were washed to remove loosely attached sperm (always under the same conditions by pipetting five times with an automatic pipette in a four-well plate with $500 \mu \mathrm{l}$ of medium), fixed, and stained with Hoechst for evaluation.

\section{Pig embryo culture}

At 4 hpi, putative zygotes were washed three times in NCSU23 previously equilibrated overnight, transferred to a four-well Nunc multidish containing $500 \mu \mathrm{l} \mathrm{NCSU}-23$ per well, and incubated at $38.5{ }^{\circ} \mathrm{C}$ and $5 \% \mathrm{CO}_{2}$ in $100 \%$ humidified air. At 48 and 168 hpi, cleavage rate (two- to four-cell embryos) and blastocyst formation, respectively, were evaluated under a stereomicroscope. 


\section{Hoechst staining}

Putative zygotes were fixed for $30 \mathrm{~min}(0.5 \%$ glutaraldehyde in DPBS), stained for 15 min (1\% Hoechst 33342 in DPBS), washed in DPBS containing $1 \mathrm{mg} / \mathrm{ml}$ polyvinylpyrrolidone, and mounted on glass slides. Samples were examined under an epifluorescence microscope at $200 \times$ and 400 $X$ magnifications. The number of spermatozoa bound to the $Z P$, penetration status, number of penetrated spermatozoa per oocyte, and pronuclear formation were assessed in each oocyte.

\section{Experimental design}

The experiments were designed to reach directly the proposed objectives: i) to study how DSP used at different concentrations affects pre-fertilization ZP hardening, sperm binding to ZP and IVF in cattle (experiment 1); ii) to evaluate the effect of different concentrations of BS3 in ZP hardening and IVF both in cattle (experiment 2) and pig (experiment 3); and iii) to check whether DSP or BS3, after demonstrating to improve IVF output in any species, affects in vitro embryo development (experiment 4). Based on the obtained results and our previous observations (Coy et al. 2008a), only DSP was assessed on pig embryo production.

Experiment 1: effect of different DSP concentrations on cow ZP resistance to pronase, sperm-ZP binding, and IVF output

Groups of 50 in vitro matured bovine oocytes were incubated for $30 \mathrm{~min}$ at $38.5{ }^{\circ} \mathrm{C}$ under $5 \% \mathrm{CO}_{2}$ in air with DSP at 0.06 , 0.3 , or $0.6 \mathrm{mg} / \mathrm{ml}$. A control group was incubated under the same conditions without DSP. After incubation, the ZP resistance to pronase was assessed in an aliquot of the oocytes and the remaining ones were subjected to IVF. IVF variables (penetration, male pronuclear formation, and monospermy percentages and mean number of sperm per penetrated oocyte) were recorded. In addition, we decided also to record the number of sperm-ZP binding in cow, since previous studies showed a reduced fertilization in bovine oocytes treated with cross-linkers before IVF (Coy et al. 2008a). Therefore, one hypothesis to be studied would be whether the cross-linker reduces the binding of the spermatozoa to the ZP. This experiment was replicated four times.

Experiment 2: effect of different BS3 concentrations on cow $Z P$ resistance to pronase, sperm-ZP binding, and IVF efficiency

In this experiment, we checked the effect of different BS3 concentrations $(0.06,0.3$, or $0.6 \mathrm{mg} / \mathrm{ml})$ following the same design than in the experiment 1 . Briefly, after incubation with BS3, an aliquot of the oocytes was used to assess the ZP resistance to pronase and the remaining oocytes were subjected to IVF. IVF variables and the number of sperm bound to ZP were recorded. This experiment was carried out in three replicates.
Experiment 3: effect of different BS3 concentrations on pig ZP resistance to pronase and IVF efficiency

Porcine IVM oocytes were incubated with the same concentrations of BS3 and conditions as in experiment 2. Then, the ZP resistance to pronase was assessed in an aliquot of oocytes and the remaining ones were subjected to IVF. IVF variables (penetration, male pronuclear formation, and monospermy percentages and mean number of sperm per penetrated oocyte) were recorded. Three replicates were made of this experiment.

Experiment 4: effect of DSP on pig embryo production using an optimized IVF system

A final experiment was designed to examine the effect on embryo development of the cross-linker treatment that had showed a positive effect on IVF efficiency. In concordance with our observations (Coy et al. 2008a) and the results of experiments 1, 2, and 3, the only treatment showing an increase in the final IVF output was the DSP in pig oocytes (Table 4). Therefore, a final experiment was run under optimized cross-linker and IVF conditions to find out the effect of DSP on porcine embryo production. Oocytes were treated with the lowest DSP concentration $(0.06 \mathrm{mg} / \mathrm{ml})$ and a control group was kept in TALPp medium without cross-linker. The IVF system was optimized by using a short time gamete coculture (15 min) and transferring the putative zygotes to NCSU-23 at $4 \mathrm{hpi}$. At $48 \mathrm{hpi}$, cleavage rate was evaluated and the putative embryos were cultured until day 7 post-insemination. This experiment was replicated four times with a total of 185 oocytes in the control group and 195 oocytes in the DSP group. Using the same conditions, we did three more replicates to check the effect in IVF parameters, which could not be analyzed in the replicates for embryo production, because it requires oocyte fixation.

\section{Statistical analysis}

Data are presented as the mean \pm S.E.M. and all percentages were modelled according to the binomial model of variables. The variables in all the experiments were analyzed by one-way or two-way ANOVA (ZP digestion time, mean number of sperm cells bound to each ZP, percentage of oocyte penetration, male pronuclear formation, mean number of sperm cells per penetrated oocyte, percentage of monospermy, cleavage rate, and percentage of blastocysts). When ANOVA revealed a significant effect, values were compared using Tukey's test. A $P$ value $<0.05$ was taken to denote statistical significance.

\section{Declaration of interest}

The authors declare that there is no conflict of interest that would prejudice the impartiality of this scientific work.

\section{Funding}

This work was supported by the Spanish Ministry of Education and Science and FEDER (AGL2006-03495). 


\section{Acknowledgements}

The authors thank R H F Hunter and N Satake for critical review of this manuscript and for their help with English spelling. The authors would like to thank Breeders Association 'Asturiana de Valle' (ASEAVA) for providing the bull semen and the staff of the slaughterhouses Orihuela and El Pozo for supplying the ovaries.

\section{References}

Aitken RJ \& Vernet P 1998 Maturation of redox regulatory mechanisms in the epididymis. Journal of Reproduction and Fertility $\mathbf{5 3}$ 109-118.

Araki Y, Nohara M, Yoshida-Komiya H, Kuramochi T, Ito M, Hoshi $H$, Shinkai Y \& Sendai Y 2003 Effect of a null mutation of the oviductspecific glycoprotein gene on mouse fertilization. Biochemical Journal 374 551-557.

Austin CR \& Braden AW 1953 Polyspermy in mammals. Nature 172 82-83. van Beneden E 1875 La maturation de l'óeuf, la fécondation et les premiéres phases du développement embryonnaire des mammíferes d'aprés des recherches faites chez le lapin. Bulletin de l'Académie royale de médecine de Belgique 40 686-736.

Bielanski A, Lutze-Wallace CL \& Nadin-Davis S 2003 Adherence of bovine viral diarrhea virus to bovine oocytes and embryos with a hardened zona pellucida cultured in vitro. Canadian Journal of Veterinary Research $=$ Revue Canadienne de Recherche Vétérinaire 67 48-51.

Boni R, Gualtieri R, Talevi R \& Tosti E 2007 Calcium and other ion dynamics during gamete maturation and fertilization. Theriogenology $\mathbf{6 8}$ S156-S164.

Broermann DM, Xie S, Nephew KP \& Pope WF 1989 Effects of the oviduct and wheat germ agglutinin on enzymatic digestion of porcine zona pellucidae. Journal of Animal Science 67 1324-1329.

Coy P \& Romar R 2002 In vitro production of pig embryos: a point of view. Reproduction, Fertility and Development 14 275-286.

Coy P, Gadea J, Romar R, Matas C \& Garcia E 2002 Effect of in vitro fertilization medium on the acrosome reaction, cortical reaction, zona pellucida hardening and in vitro development in pigs. Reproduction 124 279-288.

Coy P, Romar R, Payton RR, McCann L, Saxton AM \& Edwards JL 2005 Maintenance of meiotic arrest in bovine oocytes using the S-enantiomer of roscovitine: effects on maturation, fertilization and subsequent embryo development in vitro. Reproduction 129 19-26.

Coy P, Grullon L, Canovas S, Romar R, Matas C \& Aviles M 2008a Hardening of the zona pellucida of unfertilized eggs can reduce polyspermic fertilization in the pig and cow. Reproduction 135 19-27.

Coy P, Canovas S, Mondejar I, Saavedra MD, Romar R, Grullon L, Matas C \& Aviles M 2008b Oviduct-specific glycoprotein and heparin modulate sperm-zona pellucida interaction during fertilization and contribute to the control of polyspermy. PNAS 105 15809-15814.

Dean J 2007 The enigma of sperm-egg recognition in mice. Society of Reproduction and Fertility Supplement 63 359-365.

Ducibella T, Kurasawa S, Rangarajan S, Kopf GS \& Schultz RM 1990 Precocious loss of cortical granules during mouse oocyte meiotic maturation and correlation with an egg-induced modification of the zona pellucida. Developmental Biology 137 46-55.

Ducibella T, Kurasawa S, Duffy P, Kopf GS \& Schultz RM 1993 Regulation of the polyspermy block in the mouse egg: maturation-dependent differences in cortical granule exocytosis and zona pellucida modifications induced by inositol 1,4,5-trisphosphate and an activator of protein kinase C. Biology of Reproduction 48 1251-1257.

Florman HM \& Ducibella T 2006 Fertilization in mammals. In Knobil and Neill's Physiology of Reproduction, 3 edn, pp 55-112. Ed. JD Neill. St Louis, MO: Elsevier Academic Press.

Fulka J Jr, Pavlok A \& Fulka J 1982 In vitro fertilization of zona-free bovine oocytes matured in culture. Journal of Reproduction and Fertility 64 495-499.
Funahashi H \& Romar R 2004 Reduction of the incidence of polyspermic penetration into porcine oocytes by pretreatment of fresh spermatozoa with adenosine and a transient co-incubation of the gametes with caffeine. Reproduction 128 789-800.

Funahashi H, Cantley TC \& Day BN 1997 Synchronization of meiosis in porcine oocytes by exposure to dibutyryl cyclic adenosine monophosphate improves developmental competence following in vitro fertilization. Biology of Reproduction 57 49-53.

Gianfortoni JG \& Gulyas BJ 1985 The effects of short-term incubation (aging) of mouse oocytes on in vitro fertilization, zona solubility, and embryonic development. Gamete Research 11 59-68.

Green D 1997 Three-dimensional structure of the zona pellucida. Reviews of Reproduction 2 147-156.

Hancock JL 1959 Polyspermy of pig ova. Animal Production 1 103-106.

Hao Y, Mathialagan N, Walters E, Mao J, Lai L, Becker D, Li W, Critser J \& Prather RS 2006 Osteopontin reduces polyspermy during in vitro fertilization of porcine oocytes. Biology of Reproduction 75 726-733.

Hao Y, Murphy CN, Spate L, Wax D, Zhong Z, Samuel M, Mathialagan N, Schatten H \& Prather RS 2008 Osteopontin improves in vitro development of porcine embryos and decreases apoptosis. Molecular Reproduction and Development 75 291-298.

Hedrick JL 2007 A comparative analysis of molecular mechanisms for blocking polyspermy: identification of a lectin-ligand binding reaction in mammalian eggs. Society of Reproduction and Fertility 63 409-419.

Hunter RH 1990 Fertilization of pig eggs in vivo and in vitro. Journal of Reproduction and Fertility 40 211-226.

Iwamoto K, Ikeda K, Yonezawa N, Noguchi S, Kudo K, Hamano S, Kuwayama M \& Nakano M 1999 Disulfide formation in bovine zona pellucida glycoproteins during fertilization: evidence for the involvement of cystine cross-linkages in hardening of the zona pellucida. Journal of Reproduction and Fertility 117 395-402.

Iwata H, Shiono H, Kon Y, Matsubara K, Kimura K, Kuwayama T \& Monji Y 2008 Effects of modification of in vitro fertilization techniques on the sex ratio of the resultant bovine embryos. Animal Reproduction Science 105 234-244.

Ko CS, Ding DC, Chu TW, Chu YN, Chen IC, Chen WH \& Wu GJ 2008 Changes to the meiotic spindle and zona pellucida of mature mouse oocytes following different cryopreservation methods. Animal Reproduction Science 105 272-282.

Kolbe T \& Holtz W 2005 Differences in proteinase digestibility of the zona pellucida of in vivo and in vitro derived porcine oocytes and embryos. Theriogenology 63 1695-1705.

Kouba AJ, Abeydeera LR, Alvarez IM, Day BN \& Buhi WC 2000 Effects of the porcine oviduct-specific glycoprotein on fertilization, polyspermy, and embryonic development in vitro. Biology of Reproduction 63 242-250.

Lonergan P \& Fair T 2008 In vitro-produced bovine embryos: dealing with the warts. Theriogenology 69 17-22.

Machaty Z, Day BN \& Prather RS 1998 Development of early porcine embryos in vitro and in vivo. Biology of Reproduction 59 451-455.

Martus NS, Verhage HG, Mavrogianis PA \& Thibodeaux JK 1998 Enhancement of bovine oocyte fertilization in vitro with a bovine oviductal specific glycoprotein. Journal of Reproduction and Fertility 113 323-329.

Miller DJ, Shi X \& Burkin H 2002 Molecular basis of mammalian gamete binding. Recent Progress in Hormone Research 57 37-73.

Nagai T, Funahashi H, Yoshioka K \& Kikuchi K 2006 Up date of in vitro production of porcine embryos. Frontiers in Bioscience: a Journal and Virtual Library 11 2565-2573.

Nara M, Yonezawa N, Shimada T, Takahashi K, Tanokura M, Yumoto F, Nakagawa H, Ohashi K, Hamano S \& Nakano M 2006 Fourier transform infrared spectroscopic analysis of the intact zona pellucida of the mammalian egg: changes in the secondary structure of bovine zona pellucida proteins during fertilization. Experimental Biology and Medicine 231 166-171.

Nixon B, Aitken RJ \& McLaughlin EA 2007 New insights into the molecular mechanisms of sperm-egg interaction. Cellular and Molecular Life Sciences 64 1805-1823.

Orsi NM, Gopichandran N, Leese HJ, Picton HM \& Harris SE 2005 Fluctuations in bovine ovarian follicular fluid composition throughout the oestrous cycle. Reproduction 129 219-228. 
Parrish J, Susko-Parrish JL, Leibfried-Rutledge ML, Critser ES, Eyestone WH \& First NL 1986 Bovine in vitro fertilization with frozen-thawed semen. Theriogenology 25 591-600.

Pate BJ, White KL, Chen D, Aston KI, Sessions BR, Bunch TD \& Weimer BC 2008 A novel approach to identify bovine sperm membrane proteins that interact with receptors on the vitelline membrane of bovine oocytes. Molecular Reproduction and Development 75 641-649.

Perry GH 2007 Risk assessment of transmission of bovine viral diarrhea virus (BVDV) in abattoir-derived in vitro produced embryos. Theriogenology 68 38-55.

Petters RM \& Wells KD 1993 Culture of pig embryos. Journal of Reproduction and Fertility 48 61-73.

Pursel VG \& Johnson LA 1975 Freezing of boar spermatozoa: fertilizing capacity with concentrated semen and a new thawing procedure. Journal of Animal Science 40 99-102.

Rankin TL, Coleman JS, Epifano O, Hoodbhoy T, Turner SG, Castle PE, Lee E, Gore-Langton R \& Dean J 2003 Fertility and taxon-specific sperm binding persist after replacement of mouse sperm receptors with human homologs. Developmental Cell 5 33-43.

Rath D, Long CR, Dobrinsky JR, Welch GR, Schreier LL \& Johnson LA 1999 In vitro production of sexed embryos for gender preselection: high-speed sorting of X-chromosome-bearing sperm to produce pigs after embryo transfer. Journal of Animal Science 77 3346-3352.

Topfer-Petersen E \& Calvete JJ 1995 Molecular mechanisms of the interaction between sperm and the zona pellucida in mammals: studies on the pig. International Journal of Andrology 2 20-26.

Vincent C, Pickering SJ \& Johnson MH 1990 The hardening effect of dimethylsulphoxide on the mouse zona pellucida requires the presence of an oocyte and is associated with a reduction in the number of cortical granules present. Journal of Reproduction and Fertility 89 253-259.

Wang WH, Day BN \& Wu GM 2003 How does polyspermy happen in mammalian oocytes? Microscopy Research and Technique 61 335-341.

Wang ZG, Yu SD \& Xu ZR 2007 Improvement in bovine embryo production in vitro by treatment with green tea polyphenols during in vitro maturation of oocytes. Animal Reproduction Science 100 22-31.

Wassarman PM, Jovine L, Qi H, Williams Z, Darie C \& Litscher ES 2005 Recent aspects of mammalian fertilization research. Molecular and Cellular Endocrinology 234 95-103.

Wong JL \& Wessel GM 2006 Defending the zygote: search for the ancestral animal block to polyspermy. Current Topics in Developmental Biology 72 1-151.

Yanagimachi R 1994 Mammalian fertilization. In The Physiology of Reproduction, 2 edn, p 189. Eds E Knobil \& JD Neil. New York: Raven Press.

Yazawa H, Radaelli G \& Yanagimachi R 1995 Comparison of the acrosome reaction-inducing ability of the outer and inner surfaces of the zona pellucida and oolemma: a study using the golden hamster. Zygote $\mathbf{3}$ 295-303.

Received 10 August 2008

First decision 23 October 2008

Revised manuscript received 1 February 2009

Accepted 4 March 2009 